\title{
Antifungal potential of cinnamon essential oils against Phytophthora colocasiae causing taro leaf blight
}

\author{
Zhang Hong ${ }^{*}{ }^{\circledR}$, Kalhoro Muhammad Talib ${ }^{\dagger}$, Kalhoro Ghulam Mujtaba, Hou Dabin, Faqir Yahya, \\ Zhou Congying and Wang Fukai
}

\begin{abstract}
Background: Taro leaf blight, caused by a severely destructive oomycete fungus Phytophthora colocasiae, is responsible for threatening yield loss worldwide. The pathogen has the ability to germinate and spread rapidly to other plants during favorable conditions resulting in acute decline and even death, causing $100 \%$ crop loss. Farmers usually rely on highly toxic systemic fungicides to control the disease, which is effective, but residual effects and resistance of these agrochemicals is still a concern. Recently as returning to nature people tend to use chemical-free products, especially edible stuff produced in organic agriculture. Therefore, the use of bio-pesticides and phytochemicals is gaining special attention by scientists as they are ecofriendly non-hazardous, sustainable, and potent alternatives to control many virulent plant pathogens The present research was conducted to assess the antifungal potential of cinnamon essential oils against $P$. colocasiae.
\end{abstract}

Materials and methods: The essential oils from cinnamon bark were extracted using microwave-assisted hydrodistillation equipment, and then their chemical constituents were evaluated using ATR FTIR spectroscopy. The antifungal potential of essential oil was assessed against mycelium, sporangia, zoospore, leaf necrosis, and corms lesions under laboratory conditions at, $0.156,0.312,0.625,1.25,2.5,5.0 \mathrm{mg} / \mathrm{mL}$ concentrations. Hymexazol was used as positive control and no essential oil as negative control, while each treatment have three replications and experiment repeated twice.

Results: The main component of oil was identified as cinnamaldehyde. The pathogen isolated from infected taro leaves was identified as P.colocasiae and then was used as a test fungus in the current study. Repeated experiments show maximum inhibition percentage of mycelial growth, zoospore germination, and sporulation of the fungus were observed at $0.625 \mathrm{mg} / \mathrm{mL}$, whereas leaf necrosis was $100 \%$ inhibited at $1.25 \mathrm{mg} / \mathrm{mL}$ concentration.

Conclusion: This research can be a reference for easy, cost-effective and environment-friendly management and control of taro leaf blight with phytochemicals and plant essential oil derivatives.

Keywords: Taro leaf blight, Phytophthora colocasiae, Cinnamon essential oil, Phytochemicals

*Correspondence: zhanghong316@nwafu.edu.cn

'Zhang Hong and Kalhoro Muhammad Talib contributed equally

College of Agriculture, School of Life Science and Engineering, Southwest

University of Science and Technology, Mianyang 621000, Sichuan, China

\section{Background}

Taro (Colocasia esculenta L.) from the family Araceae is one of the oldest tuber cultivated crops [1], widely planted in pacific islands, Africa, Asia, West Indies, and South America [2]. Taro is rich in carbohydrates, proteins, minerals, and vitamins and is an important staple food for people of Southeast Asia, China, United States, 
and especially in Africa [3]. Taro also has a medicinal potential against many pathogenic and bacterial infectious human diseases [4]. The Food and Agriculture Organization estimates the world's taro production about 10.64 billion tons, with China producing about 1.95 billion tons, ranking second in the world following Africa [5].

Taro is susceptible to more than 23 different pathogens, severely affecting plant growth and reducing yield. Among them, taro leaf blight (Phytophthora colocasiae) is the most devastating one that threatens sustainable production and yield [6]. Leaf blight in taro was first reported in Taiwan and China in 1911; recently, the disease is frequent and tends to cause substantial yield loss to the crop in the region [7]. The disease occurs in warmer conditions, mostly visible on plant leaves, symptoms appear between 2 and 4 days after infestation. Initially, it appears as a small water stain, and then the area of water stains increases in size and number [8]. As the disease develops, the lesions expand, and the shape becomes earthy and color turns to dark brown showing a yellow edge. In dry weather, the lesions become papery and show a shot hole appearance. In hot and humid conditions, mature taro leave are destroyed within 10 days and is even more rapid in severe cases. The production loss around 50-60\%, sometimes resulting in severe decay of corms before or after harvesting; susceptible varieties can be destroyed completely bearing $100 \%$ loss [9].

Leaf blight of taro caused by an oomycete fungus (Phytophthora colocasiae) has a complex life cycle according to growth characteristics, which are facultative parasite (hemibiotrophic), pathogenic, (biotrophic), and saprophytic (necrotrophic) stage [10]. It survives from 15 to $35{ }^{\circ} \mathrm{C}$, favorable temperature is $25-30{ }^{\circ} \mathrm{C}$ when the nocturnal temperature is around $20^{\circ} \mathrm{C}$, and the humidity is more than 90\%; that encourages zoospores germination conducive to its epidemic. P. colocasiae is a heterothallic species producing sporangia, sporangiophores, and zoospores asexually; meanwhile, it produces oospores sexually that remain within plant debris and corms for the next crop season. Sometimes, cell walls of zoospores are thickened and produce chlamydospores that enter a dormant state for prolonged viability in the soil as well as in corms [11]. This phenomenon makes taro disease as a key pathogen, and continuous cropping harbors field biomass of pathogen constantly accumulating in the soil.

The pathogen has the ability to germinate and spread rapidly to other plants during favorable conditions resulting in acute decline and even death, causing $100 \%$ crop loss [12]. Farmers usually rely on highly toxic systemic fungicides to control the disease, which is effective, but residual effects and resistance of these agrochemicals' may not be ignored. Recently, people tend to use chemical-free products, especially edible compounds produced in organic agriculture. Therefore, the use of bio-pesticides and phytochemicals is gaining special attention by scientists as they are ecofriendly non-hazardous, sustainable, and potent alternatives to control many virulent plant pathogens [13].

Essential oils, sometimes referred to as ethereal oils, essences or volatiles, are metabolic compounds secreted by many organisms, especially plants [14]. These oils are mostly extracted from the materials that comprise distillation, pressure, or extracted by appropriate solvent [15]. These oils are commonly used in perfumes, food compounds, cosmetics, and medicinal purposes based on their nature and properties [16]. The biochemical composition of these plant oils varies in different regions where they grow and environmental circumstances. Besides this, different techniques used for drying materials, extraction, and distillation also affect the essential oil composition [17]. Besides their delightful aromas, these oils are also valued for their bioactive compounds and properties they show in several ways [18]. Previously, essential oils were obtained by conventional hydrodistillation [19], that may affect the oil quality because some volatile components may be lost in the course of the process, low extraction efficacy, and deprivation of unsaturated composites due to temperatures and nature of the solvent used for extraction [20].

A novel, innovative technique, i.e., microwave extraction has gained attention and uses small compact equipment with controlled heating systems [21]. The fundamental advantage of microwave-assisted extraction is cost-effective, saving extraction time, environmentfriendly, chemical-free, and avoids solvent use [22].

Cinnamon (Cinnamomum zeylanicum) essential oils possess great potential in antimicrobial activity and are applied as a natural remedy for treating and preventing many plant diseases [23]. As no systematic studies, have been done on the pesticidal properties of cinnamon essential oils against taro leaf blight, therefore, this study is novel and first attempt. This study intends to find an easy to operate method for extracting essential oil for safe and comfortable use against plant pathogens for sustainable agriculture.

\section{Materials and methods \\ Plant material}

In view of the previous literature [24], cinnamon bark was selected for this study, collected from the horticultural garden of Southwest University of Science and Technology Mianyang Sichuan China during the summer of 2020. Freshly collected bark was washed and kept in a ventilated shadow place at room temperature to dry. Before extraction, it was crushed into a coarse powder 
using a kitchen blender and added water to desired quantity for soaking overnight.

\section{Extraction of essential oil (EO)}

Extraction of cinnamon bark essential oil was obtained by modified microwave-assisted hydrodistillation instrument mounted with Clevenger apparatus. This was a low-temperature microwave extraction instrument with microwave power: $800 \mathrm{~W}$ rated input power, $1.5 \mathrm{KW}$ microwave frequency: $2450 \pm 50 \mathrm{MHz}$, a maximum voltage of internal microwave generator: 4200VDC, maximum working temperature, $300{ }^{\circ} \mathrm{C}$. The capacity of the flask for plant material was $5 \mathrm{~L}$ and leak-proof pipeline to Clevenger system. The instrument was equipped with a water cooling system and circulation for condensation. The mechanical mixing function for homogenizing the plant material during extraction was also installed in the equipment. PLC color touch screen, with simple and convenient operation, closed-loop PID automatically adjusts the microwave power and can display materials in realtime temperature, microwave power, and working time and procedure (Fig. 1).

In this MAHD procedure performed at atmospheric pressure, $300 \mathrm{~g}$ of cinnamon bark soaked in $200 \mathrm{~mL}$ of water overnight, then with the addition of $300 \mathrm{~mL}$ water heated at $100{ }^{\circ} \mathrm{C}$ for $90 \mathrm{~min}$. This period was sufficient to extract all the essential oils from the samples. Each extraction was performed at least three times. The extracted oil was collected in $5 \mathrm{~mL}$ bottles, dried over anhydrous sodium sulfate, and covered with aluminum foil, stored at $4{ }^{\circ} \mathrm{C}$ until further use.

\section{Essential oil analysis (ATR-FTIR spectroscopy)}

The main components of the obtained EO were identified by using the Fourier-transform infrared spectroscopy (FTIR) using a (Spectrum Two ${ }^{\mathrm{TM}}$ FT-IR Spectrometer and Analysis Systems, PerkinElmer USA) following ATR (attenuated total reflectance) process. Spectra were evaluated using an Aldrich FTIR collection Edition II

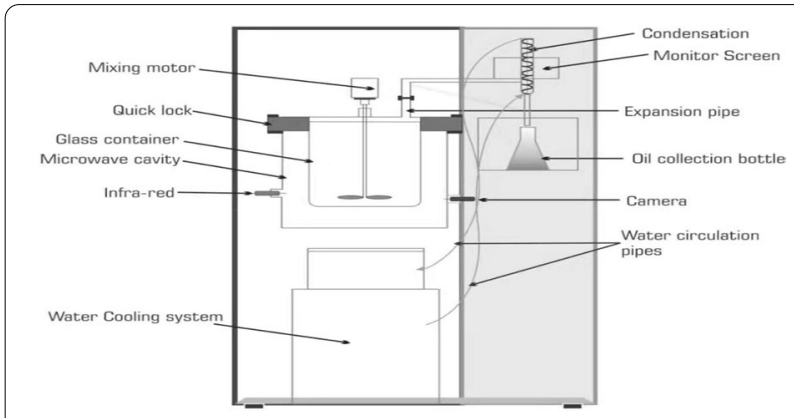

Fig. 1 Microwave-assisted hydrodistillation (MAHD) setup model software (Thermo Fisher Scientific Inc USA). A single droplet of essential oil sample is carefully retained on the surface of the diamond ATR crystal, and the spectrum observed on the computer monitor and saved. The process repeated three times.

\section{Pathogen isolation}

The causal organism of disease was isolated from infected leaves showing characteristic symptoms of blight (Fig. 2A), following the method suggested by [25]. Infected leaves were cut into pieces of $5-10 \mathrm{~mm}^{2}$ near the lesion's margins, sterilized in $75 \%$ ethanol for one min, and then washed twice in sterilized $\mathrm{DDH}_{2} \mathrm{O}$. Leaf pieces were dried on sterile blotting paper transferred to PDA plates aseptically and incubated at $25{ }^{\circ} \mathrm{C}$. As soon, the mycelium emerged from leaf pieces, it was shifted to a fresh PDA medium to ensure pure culture (Fig. 2D).

This pure culture of the fungus isolate was identified as Phytophthora colocasiae based on pathogenicity, growth pattern, sporangial appearances, and microscopic criteria as described by [26, 27] (Fig. 2). Pathogenicity of fungus was confirmed to satisfy Koch's postulates. The pure culture was kept in storage at $4{ }^{\circ} \mathrm{C}$ and transferred to fresh PDA media every month for maintenance.

\section{In vitro antifungal assay \\ Mycelial inhibition assessment}

The antifungal potential of essential oil was assessed against isolated pathogen by poison food method described by Lahlou (2004). Oil was diluted with dimethyl sulfoxide (DMSO) as 9:1(v/v) as stock solution, while added to PDA to obtain final concentrations i.e., 5, 2.5, 1.25, $0.625 \mathrm{mg} / \mathrm{mL}$. Pre-sterilized $9 \mathrm{~cm}$ Petri dishes poured with $10 \mathrm{~mL}$ PDA media, each with four replications of each treatment. PDA medium was contained with DMSO to serve as a negative control, whereas fungicide (Hymexazol) was added with PDA with the same concentrations to serve as a positive control. A control treatment was PDA alone to compare all the treatments. The Petri dishes were inoculated with a $0.5 \mathrm{~cm}$ disc from the edge of a freshly grown mycelial culture of isolated pathogen and kept for incubation at $25^{\circ} \mathrm{C}$. The antifungal potential of essential oils was assessed when the control treatment Petri dishes were fully grown. Mycelium growth inhibition percentage $(I)$ was calculated by subtracting the diameter of radial colony growth of treated plates $\left(D_{\mathrm{t}}\right)$ from negative control Petri plates $\left(D_{\mathrm{ck}}\right.$. $\left(\mathrm{I}=D_{\mathrm{ck}}-D_{\mathrm{t}}\right)$ [28]. The experiment consisted of four replications, and the process repeated twice for result authentication. 

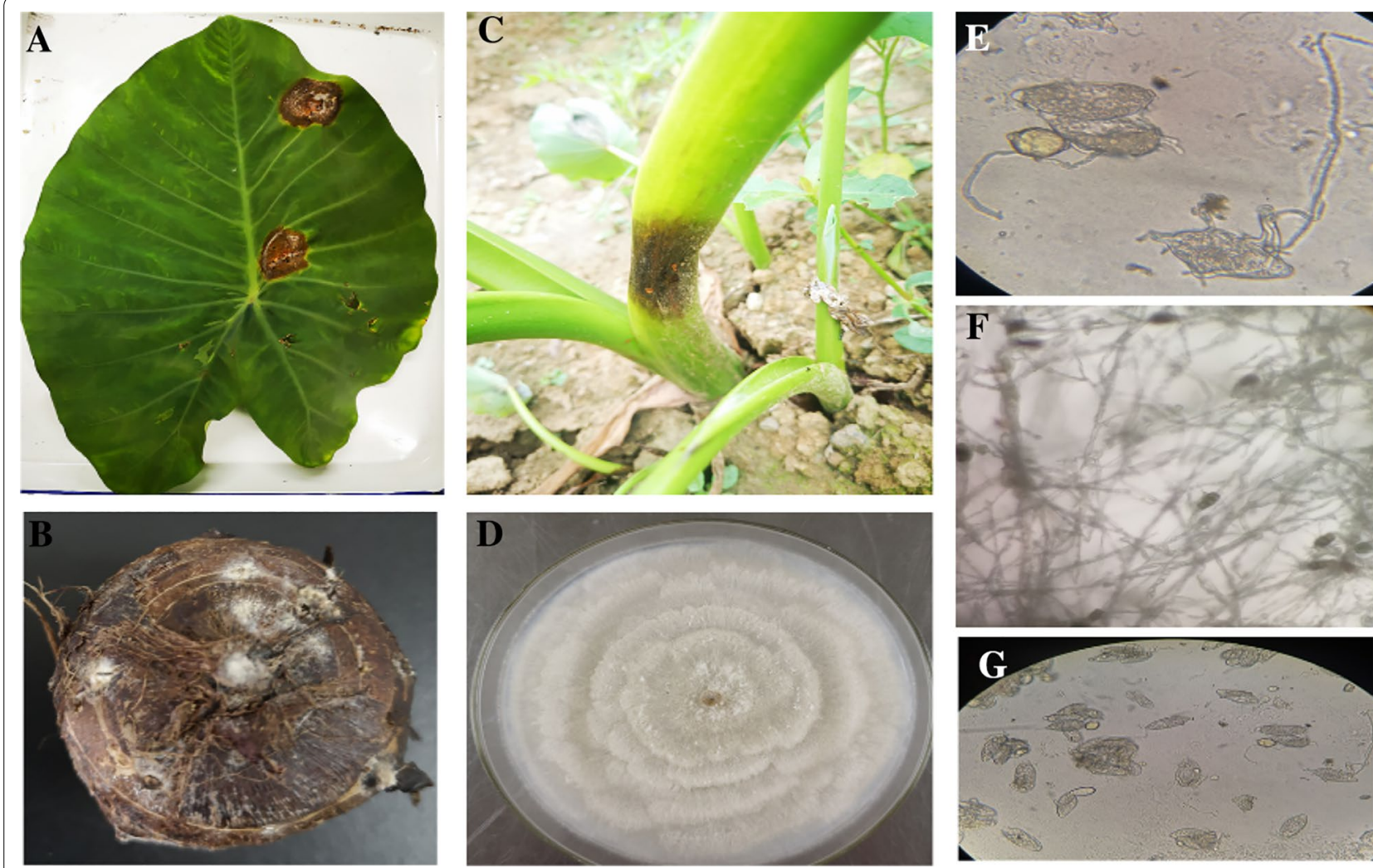

Fig. 2 The typical symptoms and morphological characteristics of P. colocasiae. A leaf blight symptoms, B Symptoms on Corms, C Lesions on leaf petioles, $\mathbf{D}$ colony pattern on PDA, E Sporangia from leaf, $\mathbf{F}$ Mycelium under the microscope, $\mathbf{G}$ sporangia from culture

\section{Inhibition of sporangium formation}

Measurement of sporangium production was done invitro on Czapek's agar (CZA) medium, supplemented with essential oils at different variable applications used before for the mycelium inhibition. Five discs of $10 \mathrm{~mm}$ from a 1-week-old pure culture of isolated fungus were homogenized into $10 \mathrm{~mL} \mathrm{DDH}_{2} \mathrm{O}$ and centrifuged at $3000 \mathrm{rpm}$ for $5 \mathrm{~min}$. The precipitate of sporangia was counted with a hemocytometer in $10 \mu \mathrm{L}$, and inhibition was compared with control treatment using a formula, [Is $\left.=\left(\mathrm{N}_{0}-\mathrm{Nx}\right) / \mathrm{Nx} \times 100\right]$ where $\mathrm{N}_{0}$ is control and $\mathrm{Nx}$ are treated with oils. Germination verified after $3 \mathrm{~h}$ for zoospores and $24 \mathrm{~h}$ for sporangia. Fungicide treatment was kept as a positive control and adopted from [12] with little modification. Every treatment had four replications, and the experiment repeated twice for confirmation.

\section{Inhibition of zoospore germination}

Inhibition of Sporangium and zoospores germination was estimated by the technique adopted from Sameza [28] with slight modifications. Essential oils were diluted in DMSO, whereas fungicide in sterilized distilled water, supplemented to V8 broth medium with same concentrations described before, and poured in test tubes. Pathogen suspension of 1-week-old culture adjusted to $10^{6}$ cell $/ \mathrm{mL}$ was inoculated in test tubes with $500 \mu \mathrm{L}$ and incubated at $25^{\circ} \mathrm{C}$ zoospore germination percentage was observed under a microscope after $3 \mathrm{~h}$ and the next day for sporangia using a hemocytometer. Every treatment had three replications, and the experiment repeated two times.

\section{Inhibition of symptoms on aerial parts}

Taro plants were grown as hydroponic culture in controlled aseptic conditions within an incubator. Onemonth-old plants were first treated with essential oil spray of the same concentrations, whereas fungicide treatment served as control. After $1 \mathrm{~h}$ of treatment, $10^{6}$ cells/mL zoospore suspension sprayed over the plants. Each treatment was replicated three times and covered with black polyethylene bags kept in the dark and moist place for few days until symptoms have appeared. The disease reduction index (DRI) by the essential oils was estimated using the formula: DRI $=D_{\mathrm{N}}-D_{\mathrm{O}} / D_{\mathrm{N}} \times 100$ where $D_{\mathrm{N}}$ is the necrotic area with no essential oil and $D_{\mathrm{O}}$ is the necrotic area treated with essential oil. 


\section{Inhibition of symptoms on corms}

Healthy taro corms of uniform size without any external impairment or noticeable deteriorations were selected for the experiment. Corms were washed thoroughly, surface sterilized by keeping in $75 \%$ ethanol for $1 \mathrm{~min}$, and then soaked two times for $5 \mathrm{~min}$ with sterile distilled water. Corms were treated by submersion in essential oils for $30 \mathrm{~min}$ at concentrations the same as demonstrated earlier. Phytophthora colocasiae isolated previously was used as inoculum. Three plugs of $5 \mathrm{~mm}$ deep were removed from corms in apex middle and basal parts with $5 \mathrm{~mm}$ cork borer aseptically. Abrasions were inoculated with $5 \mathrm{~mm}$ PDA slants obtained from 7-day-old pure culture then the wound was closed with the same plug removed from the taro corm. Each treatment had three replications, treated with and without fungicide served as control. Corms were kept for incubation in dark and moist conditions at $25{ }^{\circ} \mathrm{C}$ for 7 days; after a week, corms were cut vertical from inoculation sites to observe symptoms.

\section{Analysis of data}

The data were analyzed using ABM (SPSS 25) edition; results expressed in means standard deviation, the relationship between variables articulated by analysis of variance (ANOVA). The least significant difference (LSD) test was used for identification of significant differences in means. Graph charts drawn with Origin Pro 2020 (9.7.0.185) software.

\section{Results and discussion}

\section{Cinnamon essential oil analysis}

The main compound of cinnamon essential oil extracted from barks was identified as cinnamaldehyde (93.91\%) (Fig. 3); previous studies also obtained the same main compound [29]. Cinnamon, EO composition, has been extensively studied due to its various pharmacological properties, low-cost, less toxic antimicrobial products [30]. The plant has the same hydrocarbons in variable extents, with major components like cinnamaldehyde obtained from bark [31]. Cinnamon holds a multifaceted and extensive history of use as an antifungal and antibacterial. Hence, cinnamon oil has various diverse oils with various features, which defines its significance in different industries [32].

\section{Cinnamon EO against mycelium growth of $P$. colocasiae}

Our experiment results revealed that the mycelium growth of $P$. colocasiae was significantly $(P<0.05)$ inhibited with increased application of cinnamon essential oil (Table 1). Maximum inhibition of radial colony growth of the fungus was observed at $0.625 \mathrm{mg} / \mathrm{mL}$ and above, whereas under the same circumstances, fungicide inhibited the fungal colony growth at a concentration of $0.15 \mathrm{mg} / \mathrm{mL}$. From the treatments showing 100\% inhibition, the inoculated discs were transferred to a fresh culture medium to check mycelium's viability, which was found already killed.

This is the first attempt to evaluate the antifungal potential of cinnamon essential oil against P. colocasiae, but there are certain reports about the antimicrobial properties of cinnamon oils. These oils possess complex chemical composition of major and trace compounds responsible for antimicrobial activities. The present research evaluated cinnamaldehyde as the major component of cinnamon essential oil, which has been described to constrain several bacteria, molds, and pathogenic fungi by inhibiting ATPase wall, cell membrane structure, and cellular metabolic interactions [33]. Besides this, there are several research studies for the antifungal potential of cinnamaldehyde against wood-rot fungi [34]

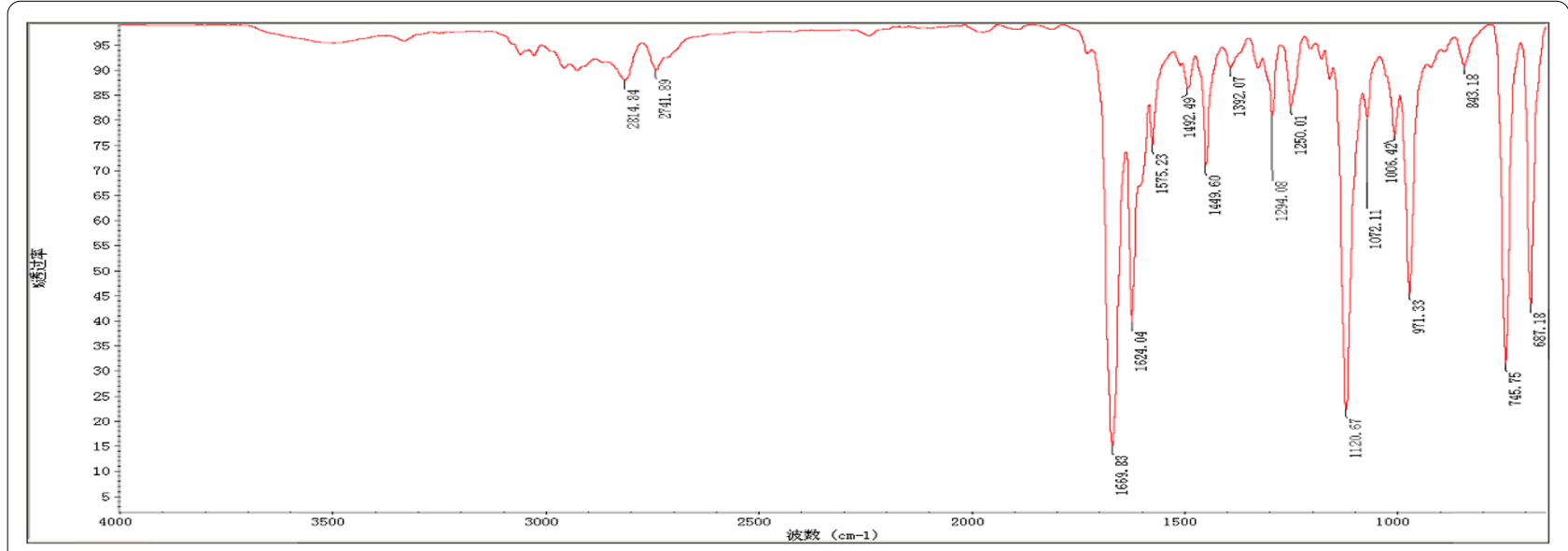

Fig. 3 FTIR spectra of cinnamon EO 
Table 1 Effect of cinnamon EO against mycelial growth and spore germination on PDA

\begin{tabular}{|c|c|c|c|c|}
\hline \multirow[t]{2}{*}{ Treatments $\mathrm{mg} / \mathrm{mL}$} & \multirow{2}{*}{$\begin{array}{l}\text { Radius of colony } \\
\text { growth }\end{array}$} & \multicolumn{3}{|c|}{ Inhibition percentage $^{1}$} \\
\hline & & Mycelium & Zoospores germination & Sporangia inhibition \\
\hline 0.00 & $45.00^{\mathrm{a}} \pm 0.00$ & $0.00^{d} \pm 0.00$ & $00.00^{d} \pm 0.00$ & $0.00^{e} \pm 0.00$ \\
\hline 0.156 & $12.55^{b} \pm 0.29$ & $72.1^{c} \pm 0.64$ & $70.02^{c} \pm 1.58$ & $67.46^{d} \pm 3.09$ \\
\hline 0.312 & $6.17^{c} \pm 0.18$ & $86.2^{b} \pm 0.42$ & $84.61^{b} \pm 1.26$ & $82.66 c \pm 1.59$ \\
\hline 0.625 & $0.00^{d} \pm 0.00$ & $100^{\mathrm{a}} \pm 0.00$ & $100^{\mathrm{a}} \pm 0.00$ & $94.13^{b} \pm 0.68$ \\
\hline 1.25 & $0.00^{d} \pm 0.00$ & $100^{\mathrm{a}} \pm 0.00$ & $100^{\mathrm{a}} \pm 0.00$ & $100^{\mathrm{a}} \pm 0.00$ \\
\hline 2.5 & $0.00^{d} \pm 0.00$ & $100^{\mathrm{a}} \pm 0.00$ & $100^{\mathrm{a}} \pm 0.00$ & $100^{\mathrm{a}} \pm 0.00$ \\
\hline 5.0 & $0.00^{d} \pm 0.00$ & $100^{\mathrm{a}} \pm 0.00$ & $100^{\mathrm{a}} \pm 0.00$ & $100^{\mathrm{a}} \pm 0.00$ \\
\hline Hymexazol & $0.00^{d} \pm 0.00$ & $100^{\mathrm{a}} \pm 0.00$ & $100^{\mathrm{a}} \pm 0.00$ & $100^{\mathrm{a}} \pm 0.00$ \\
\hline
\end{tabular}

Values indicate means of four replications and dissimilar letters in the same column indicate significantly different based on LSD test $(P<0.05)$ and \pm denotes standard error

${ }^{1}$ Inhibition percentage compared with control treatment without cinnamon EO

bread preservation from Aspergillus niger [35] Fusarium sambucinum by inhibiting ergosterol biosynthesis [36]. However, the potency of the other minor compounds in cinnamon oil cannot be omitted. In this regard, [29] described that essential oils' antifungal activity could be associated with the synergistic influence of main and trivial constituents. Meanwhile, it can also suggested that the volatile compounds derived from cinnamon may have a part in the restraint of mycelial growth. Overall performance of cinnamon oil has also been reported against Candida spp. [37, 38] fungi causing respiratory tract mycoses in humans [39] pathogenic fungus of rice false smut [40].

\section{Cinnamon EO against sporangia and zoospore germination} Sporangia and zoospores germination was reduced significantly $(P<0.05)$ as the oil concentration was increased (Table 1). The minimum inhibitory application for zoospores was obtained at $0.625 \mathrm{mg} / \mathrm{mL}$ and $1.25 \mathrm{mg} /$ $\mathrm{mL}$ for sporangia germination. As observed under the microscope, a distinct change in the shape of sporangia and deformity in zoospores was observed. This is the evidence of cellular lysis of sporangia treated with oils. Sameza assessed the antifungal properties of eucalyptus essential oils against germination of $P$. colocasiae zoospores and sporangia and described the susceptibility of zoospores greater than sporangia. Since our results are parallel to the study conducted by [28] and we can justify this since zoospores do not have a biologic wall, which sporangia have. In favorable conditions, zoospores germinate, losing their flagella and becoming enclosed in a cyst-like cell wall, which produces a germ tube instigating infection course [41]. Antifungal molecules are supposed to interfere with this process of encasement and cell wall synthesis [42]. On the other hand, micro-compounds present in essential oils acts synergistically to constrain the germination for their hydrophobic properties that could enable their penetration through the cell membrane [43].

\section{Reduction of leaf necrosis by essential oil}

Definite symptoms of Leaf blight were visible on negative control treatments when observed after 7 days incubation period, whereas mild symptoms were seen where cinnamon oil was applied at concentrations of 0.156 , 0.312 , and $0.625 \mathrm{mg} / \mathrm{mL}$ (Table 2). On the other hand, leaves treated with control treatment (Hymexazol) at the dosage of $0.16 \mathrm{mg} / \mathrm{mL}$ and essential oil applications of $1.25 \mathrm{mg} / \mathrm{mL}$ and above produced no visible symptoms. The results show a substantial positive correlation within the application of essential oil and the leaf necrotic area decrease (Table 2). Apart from mycelium, zoospores are a vital lifecycle form of $P$. colocasiae, which have high significance for establishing infection. Our results may be because of antifungal compounds of cinnamon essential oil that performed lysis of zoospores and impeded their germination. Essential oils have the capacity to enhance disease resistance in plants. The mechanism of resistance is considered by an acute release of the responsive molecules $\mathrm{H}_{2} \mathrm{O}_{2}$, or oxidation stress, which is the same mechanism that happens when plants are exposed to any biotic or atmospheric stress [44]. As described before, cinnamaldehyde is the principal component of Cinnamon essential oil, which is reported to induce a reduction in the virulence in many pathogens (inhibition of germ tube establishment and in adhesion, phospholipid hydrolysis, and proteinase activity [45]. This effect may be concerned with these molecules' act on the ATPase-reliant efflux systems [46]. It can also prevent mycelia development and production of aflatoxin that primes to an irreparable alteration of hyphae structure, reducing cytoplasmic content and mitochondrial obliteration. The absorbency 
Table 2 Effect of cinnamon EO against necrosis and sporulation on leaf assay

\begin{tabular}{|c|c|c|c|c|c|}
\hline \multirow{2}{*}{$\begin{array}{l}\text { Treatments } \\
\text { Concentration } \mathrm{mg} / \mathrm{ml}\end{array}$} & \multirow{2}{*}{$\begin{array}{l}\text { Duration } \\
\text { Hour }\end{array}$} & \multicolumn{2}{|l|}{ Leaf necrosis } & \multicolumn{2}{|l|}{ Sporulation } \\
\hline & & Diameter (mm) & Inhibition ${ }^{1} \%$ & $10^{3}$ sporangia $/ \mathrm{mL}$ & Inhibition ${ }^{1} \%$ \\
\hline 0.00 & 72 & $16.50^{\mathrm{a}} \pm 0.79$ & $0.00^{\mathrm{e}} \pm 0.00$ & $95.00^{\mathrm{a}} \pm 1.29$ & $0.00^{e} \pm 0.00$ \\
\hline 0.156 & 72 & $12.75^{b} \pm 0.85$ & $22.72^{d} \pm 5.17$ & $51.25^{b} \pm 3.06$ & $46.05^{d} \pm 3.22$ \\
\hline 0.312 & 72 & $8.95^{c} \pm 0.49$ & $45.75^{c} \pm 2.99$ & $22.75^{c} \pm 0.85$ & $76.05^{\mathrm{C}} \pm 0.89$ \\
\hline 0.625 & 72 & $3.45^{d} \pm 0.33$ & $79.09^{b} \pm 2.01$ & $14.00^{d} \pm 0.91$ & $85.26^{b} \pm 0.96$ \\
\hline 1.25 & 2 & $0.00^{e} \pm 0.00$ & $100^{\mathrm{a}} \pm 0.00$ & $0.00^{e} \pm 0.00$ & $100^{a} \pm 0.00$ \\
\hline 2.50 & 2 & $0.00^{e} \pm 0.00$ & $100^{\mathrm{a}} \pm 0.00$ & $0.00^{e} \pm 0.00$ & $100^{\mathrm{a}} \pm 0.00$ \\
\hline 5.00 & 2 & $0.00^{e} \pm 0.00$ & $100^{\mathrm{a}} \pm 0.00$ & $0.00^{e} \pm 0.00$ & $100^{\mathrm{a}} \pm 0.00$ \\
\hline Hymexazol & 2 & $0.00^{e} \pm 0.00$ & $100^{\mathrm{a}} \pm 0.00$ & $0.00^{e} \pm 0.00$ & $100^{a} \pm 0.00$ \\
\hline
\end{tabular}

Values indicate means of four replications and dissimilar letters in the same column indicate significantly different based on LSD test $(P<0.05)$ and \pm denotes standard error

${ }^{1}$ Inhibition percentage compared with control treatment without cinnamon EO

${ }^{2}$ Indicates no symptoms

triggered by these molecules concerns the oxidationreduction mechanism, which essentially controls specific signaling pathways in cells [47]. Results achieved by [12] exhibited reduced leaf necrosis more effectively in preventive application relatively than curative control with an essential oil treatment.

\section{Cinnamon EO against sporangia production}

A significant decrease in sporangia production was observed $(P<0.05)$ with increased application of essential oils (Table 2). Maximum inhibition of sporangium was attained at and above $(0.625 \mathrm{mg} / \mathrm{mL} 100 \%$ inhibition). Additionally, some morphological variations in the shape of sporangia observed where the concentration of oil application was increased compared with un-amended treatment. Essential oils indeed comprise numerous compounds that express antifungal actions against many plant pathogenic fungi [29]. These compounds show several intrusive phenomena for disease inhibition, just like deterioration of cell wall and biological membrane, resulting from high penetration and discharge of cellular components, simultaneously interfere with cell membrane functions [38]. Lipophilicity of EO constituents allow the oil to infiltrate the plasma membrane, disturb enzyme activities, and unregulated cell wall synthesis, addition high concentration of EOs comprising volatile compounds causes cell lysis, resulting in inhibition of sporangia production [42]. Various research described the inhibitory influence of cinnamon essential oils against fungal pathogens; meanwhile, it is reasonable to advise that many of the volatile compounds derived from the essential oils might have an inhibitory effect on mycelia and sporangia production. Eucalyptus oil at $0.625 \mathrm{mg} / \mathrm{L}$ [28] and citrus essential oil reduced sporangia production of P. colocasiae at a concentration of 800 ppm [12].

\section{Cinnamon EO against P. colocasiae inoculated on taro corms}

Mycelial plugs inoculated in taro corms positively showed rotting symptoms solely in negative control treatments and applications of the essential oils $1.25 \mathrm{mg} / \mathrm{mL}$ and above (Fig. 4). Fungicide treated inoculations and certain essential oil treatments did not develop lesions in the corms. Deteriorations were noticeable superficially on the corms as dark brown spots centered on the inoculation sites. Inhibition of symptoms on taro corms could result from high absorbance of volatile oils in the corms pith. Taro leaf blight, $P$. colocasiae is responsible for a severe postharvest deterioration of corms [10].

In contrast, oospores in the corms persist for an extended period, which serves as the primary inoculum, which initiates an infection that leads to epidemic situations [48]. Different mechanisms and preventive as well as curative properties of plant essential plant oils for safe and cost-effective management of postharvest diseases are studied [40]. Since essential oils are

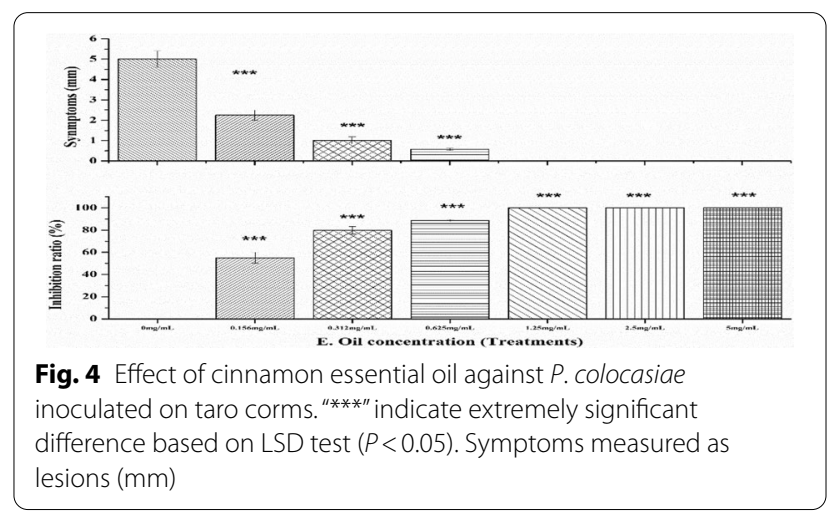


frequently used for disinfecting fruits and vegetables as well as food products for long shelf life and free from pathogens [35]

\section{Conclusion}

Leaf blight has been perceived in almost all regions where taro is cultivated, causing serious concern to farmers. Lack of proper management strategy towards crop diseases, intension of systemic fungicide use is increasing. Naturally, obtained phytochemicals could provide a widespread selection of compounds as an alternate approach for control of this disease. Our study showed that the essential oil of cinnamon prepared in the laboratory significantly inhibited mycelial growth, spore viability and germination of fungus and reduced symptoms on leaf and corms of taro. Keeping in view the hazardous effects of systematic fungicides that directly and indirectly impact human and environmental health, we conducted this research to utilize cinnamon essential oil as a potential alternative for these fungicides. In this regard, more plant essential oils should be evaluated that have potent antifungal activities. This research can be a reference for easy, cost-effective and environmentfriendly management and control of taro leaf blight with phytochemicals and plant essential oil derivatives.

\section{Abbreviations \\ EO: Essential oil; VDC: Volts of direct current; MHz: Megahertz; KW: Kilowatt; PLC: Programmable logic controller; PID: Proportional integral derivative; MAHD: Microwave-assisted hydro-distillation; FTIR: Fourier-transform infrared spectroscopy; ATR: Attenuated total reflectance; PDA: Potato dextrose agar; DDH2O: Double distilled water; DMSO: Dimethyl sulfoxide; DRI: Disease reduc- tion index.}

\section{Acknowledgements}

The authors would like to express their gratefulness to the Qingdao Fudemi biotechnology co Itd for their support.

\section{Authors' contributions}

ZH conceptualized, supervised, the study and arranged funding sources. MTK carry out all of the data analysis and wrote the manuscript. KGM assisted in graphic design. $H D, F Y, Z C$, and WF contributed in review and writing of this manuscript. All authors read and approved the final manuscript.

\section{Funding}

The National Natural Science Foundation of China (31601582) and the National Key Research and Development Program of China (2018YFD0200500) supported the research.

\section{Availability of data and materials}

The data used and/or analyzed during the current study are available from the corresponding author on rational request.

\section{Declarations}

Ethics approval and consent to participate Not applicable.

\section{Consent for publication}

Not applicable.

\section{Competing interests}

The authors have no any conflict of interest to declare.

Received: 6 May 2021 Accepted: 7 July 2021

Published online: 27 July 2021

\section{References}

1. Yin J, Jiang L, Wang L, Han X, Guo W, Li C, et al. A high-quality genome of taro (Colocasia esculenta (L.) Schott), one of the world's oldest crops. Mol Ecol Resour. 2021;21(1):68-77.

2. Ahmed I, Lockhart PJ, Agoo EM, Naing KW, Nguyen DV, Medhi DK, et al. Evolutionary origins of taro (Colocasia esculenta) in southeast Asia. Ecol Evol. 2020;10(23):13530-43.

3. Sharma S, Jan R, Kaur R, Riar CS. Taro (Colocasia esculenta). In: Nayik GA, Gull A, editors. Antioxidants in vegetables and nuts-properties and health benefits. Berlin: Springer; 2020. p. 341-53.

4. Sudhakar P, Thenmozhi V, Srivignesh S, Dhanalakshmi M. Colocasia esculenta (L.) Schott: pharmacognostic and pharmacological review. J Pharmacogn Phytochem. 2020;9(4):1382-6.

5. FAO. FAOSTAT statistical database. Food and Agriculture Organization of the United Nations. 2018. http://www.fao.org/faostat/en/\#home.

6. Bi ME, Teke AN, Christopher S, Annih MG, Charles F. Evaluation of fungicide against taro leaf blight disease caused by Phytophthora colocasiae in three agro-ecological zones of Cameroon. Asian Res J Agric. 2020. https:// doi.org/10.9734/arja/2020/v13i330102.

7. Singh D, Jackson G, Hunter D, Fullerton R, Lebot V, Taylor M, et al. Taro leaf blight - a threat to food security. Agriculture. 2012;2(3):182-203.

8. Omane E, Oduro K, Cornelius E, Opoku I, Akrofi A, Sharma K, et al. First report of leaf blight of taro (Colocasia esculenta) caused by Phytophthora colocasiae in Ghana. Plant disease. 2012;96(2):292. https://doi.org/10. 1094/PDIS-09-11-0789.

9. Takor MC, Monono EY, Ntane OA, Ngale JE, Fontem LA. Assessing taro (Colocasia esculenta (L.) Schott) leaf blight incidence, severity, and farmers' knowledge of the disease in Fako Division of Cameroon. Int J Pathog Res. 2020;5(2):17-29.

10. Alexandra S, Jamora N, Smale M, Ghanem ME. The tale of taro leaf blight: a global effort to safeguard the genetic diversity of taro in the Pacific. Food Security. 2020;12:1005-16.

11. Brooks F. Taro leaf blight. Plant Health Instr. 2015. https://doi.org/10.1094/ PHI-I-2005-0531-01.

12. Tchameni SN, Mbiakeu SN, Sameza ML, Jazet PMD, Tchoumbougnang F. Using Citrus aurantifolia essential oil for the potential biocontrol of Colocasia esculenta (taro) leaf blight caused by Phytophthora colocasiae. Environ Sci Pollut Res. 2018;25(30):29929-35.

13. Tiwari S, Chauhan PS. Ecological restoration and plant biodiversity. In: Upadhyay SK, Singh SP, editors. Bioprospecting of plant biodiversity for industrial molecules. Hoboken: Wiley; 2021.

14. Butnariu M, Sarac I. Essential oils from plants. J Biotechnol Biomed Sci. 2018;1(4):35.

15. Yousefi M, Rahimi-Nasrabadi M, Pourmortazavi SM, Wysokowski M, Jesionowski T, Ehrlich $\mathrm{H}$, et al. Supercritical fluid extraction of essential oils. TrAC Trends Anal Chem. 2019;118:182-93.

16. Irshad M, Subhani MA, Ali S, Hussain A. Biological importance of essential oils. In: El-Shemy HA, editor. Essential oils-oils of nature. London: IntechOpen; 2020.

17. Merah O, Sayed-Ahmad B, Talou T, Saad Z, Cerny M, Grivot S, et al. Biochemical composition of cumin seeds, and biorefining study. Biomolecules. 2020;10(7):1054

18. Liao M, Xiao JJ, Zhou LJ, Yao X, Tang F, Hua RM, et al. Chemical composition, insecticidal and biochemical effects of Melaleuca alternifolia essential oil on the Helicoverpa armigera. J Appl Entomol. 2017;141(9):721-8.

19. Elyemni M, Louaste B, Nechad I, Elkamli T, Bouia A, Taleb M, et al. Extraction of essential oils of Rosmarinus officinalis $L$. by two different methods: hydrodistillation and microwave assisted hydrodistillation. Sci World J. 2019. https://doi.org/10.1155/2019/3659432.

20. Chen F, Liu S, Zhao Z, Gao W, Ma Y, Wang X, et al. Ultrasound pre-treatment combined with microwave-assisted hydrodistillation of essential oils from Perilla frutescens (L.) Britt. leaves and its chemical composition and biological activity. Ind Crops Prod. 2020;143: 111908. 
21. Vinatoru M, Mason T, Calinescu I. Ultrasonically assisted extraction (UAE) and microwave assisted extraction (MAE) of functional compounds from plant materials. TrAC Trends Anal Chem. 2017;97:159-78.

22. Wang Y, Li R, Jiang Z-T, Tan J, Tang S-H, Li T-T, et al. Green and solvent-free simultaneous ultrasonic-microwave assisted extraction of essential oil from white and black peppers. Ind Crops Prod. 2018;114:164-72.

23. Choi O, Cho SK, Kim J, Park CG, Kim J. In vitro antibacterial activity and major bioactive components of Cinnamomum verum essential oils against cariogenic bacteria, Streptococcus mutans and Streptococcus sobrinus. Asian Pac J Trop Biomed. 2016;6(4):308-14.

24. Tran HN, Graham L, Adukwu EC. In vitro antifungal activity of Cinnamomum zeylanicum bark and leaf essential oils against Candida albicans and Candida auris. Appl Microbiol Biotechnol. 2020;104(20):8911-24.

25. Fokunang C, Mbong G, Manju E, Tembe-Fokunang E, Hanna R. Screen house and field resistance of taro cultivars to taro leaf blight disease (Phytophtora colocasiae). Br Biotechnol J. 2016. https://doi.org/10.9734/ bbj/2016/14317.

26. Evelyn M, Charles F, Grace M, Estella T-F, Hanna R. Evaluation of latent infection, bio-deterioration and yield of Colocasia esculenta (L.) Schott, caused by taro leaf blight disease (Phytophthora colocasiae Raciborski). J Adv Biol Biotechnol. 2017. https://doi.org/10.9734/JABB/2017/16479.

27. Lucas JA. Plant pathology and plant pathogens. Hoboken: Wiley; 2020.

28. Sameza ML, Boat MAB, Nguemezi ST, Mabou LCN, Dongmo PMJ, Boyom FF, et al. Potential use of Eucalyptus globulus essential oil against Phytophthora colocasiae the causal agent of taro leaf blight. Eur J Plant Pathol. 2014;140(2):243-50

29. Wang D, Zhang J, Jia X, Xin L, Zhai H. Antifungal effects and potential mechanism of essential oils on Collelotrichum gloeosporioides in vitro and in vivo. Molecules. 2019;24(18):3386.

30. Khan N, Shreaz S, Bhatia R, Ahmad SI, Muralidhar S, Manzoor N, et al. Anticandidal activity of curcumin and methyl cinnamaldehyde. Fitoterapia. 2012;83(3):434-40.

31. Rao PV, Gan SH. Cinnamon: a multifaceted medicinal plant. Evid Based Complement Alternat Med. 2014. https://doi.org/10.1155/2014/642942.

32. Kazemi M, Mokhtariniya S. Essential oil composition of bark of Cinnamomum zeylanicum. J Essent Oil Bear Plants. 2016;19(3):786-9.

33. Shreaz S, Wani WA, Behbehani JM, Raja V, Irshad M, Karched M, et al. Cinnamaldehyde and its derivatives, a novel class of antifungal agents. Fitoterapia. 2016;112:116-31.

34. Cheng S-S, Liu J-Y, Chang E-H, Chang S-T. Antifungal activity of cinnamaldehyde and eugenol congeners against wood-rot fungi. Biores Technol. 2008:99(11):5145-9.

35. Sun Q, Li J, Sun Y, Chen Q, Zhang L, Le T. The antifungal effects of cinnamaldehyde against Aspergillus niger and its application in bread preservation. Food Chem. 2020;317: 126405.
36. Wei J, Bi Y, Xue H, Wang Y, Zong Y, Prusky D. Antifungal activity of cinnamaldehyde against Fusarium sambucinum involves inhibition of ergosterol biosynthesis. J Appl Microbiol. 2020;129(2):256-65.

37. Goel N, Rohilla H, Singh G, Punia P. Antifungal activity of cinnamon oil and olive oil against Candida Spp. isolated from blood stream infections. J Clin Diagn Res. 2016;10(8):DC09.

38. Shahina Z, El-Ganiny AM, Minion J, Whiteway M, Sultana T, Dahms TE. Cinnamomum zeylanicum bark essential oil induces cell wall remodelling and spindle defects in Candida albicans. Fungal Biol Biotechnol. 2018;5(1):1-16.

39. Singh $H$, Srivastava M, Singh A, Srivastava A. Cinnamon bark oil, a potent fungitoxicant against fungi causing respiratory tract mycoses. Allergy. 1995;50(12):995-9.

40. Zheng J, Liu T, Guo Z, Zhang L, Mao L, Zhang Y, et al. Fumigation and contact activities of 18 plant essential oils on Villosiclava virens, the pathogenic fungus of rice false smut. Sci Rep. 2019;9(1):1-10.

41. Matheron M, Porchas M. Impact of azoxystrobin, dimethomorph, fluazinam, fosetyl-Al, and metalaxyl on growth, sporulation, and zoospore cyst germination of three Phytophthora spp. Plant Dis. 2000;84(4):454-8.

42. Bi Y, Jiang H, Hausbeck MK, Hao JJ. Inhibitory effects of essential oils for controlling Phytophthora capsici. Plant Dis. 2012;96(6):797-803.

43. Walker CA, van West P. Zoospore development in the oomycetes. Fungal Biol Rev. 2007;21(1):10-8

44. Nazzaro F, Fratianni F, Coppola R, Feo VD. Essential oils and antifungal activity. Pharmaceuticals. 2017;10(4):86.

45. Khan SN, Khan S, Iqbal J, Khan R, Khan AU. Enhanced killing and antibiofilm activity of encapsulated cinnamaldehyde against Candida albicans. Front Microbiol. 2017;8:1641.

46. Pootong A, Norrapong B, Cowawintaweewat S. Antifungal activity of cinnamaldehyde against Candida albicans. Southeast Asian J Trop Med Public Health. 2017:48(1):150-8.

47. Sun Q, Shang B, Wang L, Lu Z, Liu Y. Cinnamaldehyde inhibits fungal growth and aflatoxin $\mathrm{B} 1$ biosynthesis by modulating the oxidative stress response of Aspergillus flavus. Appl Microbiol Biotechnol. 2016;100(3):1355-64

48. Baysal-Gurel F, Cinar A. First report of leaf blight caused by Phytophthora colocasiae infecting taro in Turkey. Plant Dis. 2015;99(10):1445.

\section{Publisher's Note}

Springer Nature remains neutral with regard to jurisdictional claims in published maps and institutional affiliations.

\section{Submit your manuscript to a SpringerOpen ${ }^{\circ}$ journal and benefit from:}

- Convenient online submission

- Rigorous peer review

- Open access: articles freely available online

- High visibility within the field

Retaining the copyright to your article

Submit your next manuscript at springeropen.com 